\title{
The Presence of Family Members During Cardiopulmonary Resuscitation:
}

\author{
European federation of Critical Care Nursing associations, European Society \\ of Paediatric and Neonatal Intensive Care and European Society of Cardiology
} Council on Cardiovascular Nursing and Allied Professions Joint Position Statement

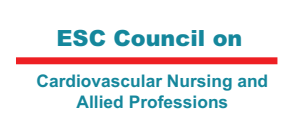

Allied Professions

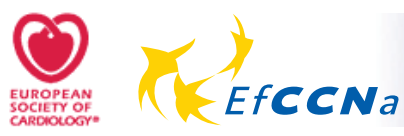

Paul Fulbrook RN; PhD, MSc, PGDipEd, BSc (Hons), Professor of Nursing, Australian Catholic University, Brisbane, Australia, Jos Latour RN; MSc, Clinical Researcher, Erasmus MC-Sophia Children's Hospital, Rotterdam, The Netherlands, John Albarran RN; MSc, BSc (Hons), NFESC, Principal Lecturer in Critical Care, University of the West of England, Bristol, UK, Wouter de Graaf RN, RCCN, President, EfCCNa,

Fiona Lynch RN; MSc, BSc, President, Scientific Committee, ESPNIC Nursing,

Denis Devictor MD; PhD, President ESPNIC,

Tone Norekvål, RN; MSc, NFESC, Chair, Council on Cardiovascular Nursing and Allied Professions;

The Presence of Family Members During Cardiopulmonary Resuscitation Working Group.

\section{COPYRIGHT STATEMENT}

Copyright of this Position Statement is jointly owned by the European federation of Critical Care Nursing associations, the European Society of Paediatric and Neonatal Intensive Care, the Council on Cardiovascular Nursing and Allied Professions, and Connect Healthcare Publishing Ltd.

This Position Statement may be reproduced for publication in any language provided that the text remains unchanged and the original source of publication is cited.

\section{CITATION}

The correct citation for this Position Statement is:

Fulbrook P, Latour J, Albarran J, Graaf de W, Lynch F, Devictor D, Norekvål T; The Presence of Family Members During Cardiopulmonary Resuscitation Working Group (2007). The Presence of Family Members During Cardiopulmonary Resuscitation: European federation of Critical Care Nursing associations, European Society of Paediatric and Neonatal Intensive Care and European Society of Cardiology Council on Cardiovascular Nursing and Allied Professions Joint Position Statement. Connect: The World of Critical Care Nursing 5 (4), 86-88.

\section{PRE-AMBLE}

The European federation of Critical Care Nursing associations (EfCCNa), the European Society of Paediatric and Neonatal Intensive Care (ESPNIC), and the European Society of Cardiology Council on Cardiovascular Nursing and Allied Professions (CCNAP) have jointly formulated this Position Statement. It was ratified by EfCCNa 28 April 2007, ESPNIC 10 February 2007, and CCNAP 16 June 2007.

This Position Statement, where possible, is based on research evidence and expert opinion as expressed in the nursing and medical literature. It is acknowledged that there is a lack of high quality research evidence on the subject of family witnessed resuscitation, and that research on this topic is particularly scarce within Europe.

\section{BACKGROUND}

The European resuscitation guidelines (Baskett et al., 2005) are supportive of family presence during cardiopulmonary resuscitation (CPR). However, this practice is often discouraged based upon paternalistic attitudes and conjecture, as opposed to empirical evidence
(Boyd, 2000; Tsai, 2002; Kissoon, 2006; Walker, 2006). Twenty years ago family members' presence during resuscitation was confined mainly to emergency departments. However, in recent years healthcare professionals are increasingly offering family members the opportunity to remain present during CPR (Jarvis, 1998; Robinson et al., 1998; Walker, 1999; Grice et al., 2003; Gold et al., 2006). Furthermore, the public demands more and more that family members should be able to remain with their loved ones during CPR, regardless of the predicted outcome of the patient (Mazer et al., 2006).

Despite changing trends, family-witnessed resuscitation is a controversial issue that is still debated widely (Albarran \& Stafford, 1999; Tasker, 2005; Kissoon, 2006). Concerns in the literature are centred on three areas. The first is the potential for family members' presence to affect the performance of resuscitation staff and increase their anxiety, or that a distressed relative might disrupt the process (Meyers et al., 2000; McClenathan et al., 2002; Blair, 2004; Weslien et al., 2006). As yet there is little evidence, other than isolated anecdotal reports to support these contentions. The second concern is that in witnessing a traumatic event, family members may experience negative emotional and psychological consequences (Crisci, 1994; Schilling, 1994; Fein et al., 2004). 
However, this concern is unconfirmed by existing evidence (Robinson et al., 1998; Meyers et al., 2000; Eichhorn et al., 2001; Holzhauser et al., 2006; Weslien et al., 2006). Furthermore, Boyd (2000) observed that many of the presumed obstacles to family members' presence, such as infringements of patient confidentiality, are theoretical debates as no such concerns have been expressed to professional regulating bodies. Third, a number of studies in Europe and elsewhere have identified that members of the public would like to be given the choice whether or not to be present and would wish, if the situation arose, to have their family member close by during CPR (Barratt \& Wallis, 1998; Meyers et al., 2000; Grice et al., 2003; Gulla et al., 2004). The positive benefits of having family members present during CPR have been documented in several studies. These benefits include the development of a bond with the resuscitation team, the provision of a more humane atmosphere that allows for closure (Robinson et al., 1998; Van der Woning, 1999; Eichhorn et al., 2001) and the satisfaction of knowing that their family member is in safe hands (Wagner, 2004).

Two European surveys, undertaken in collaboration with EfCCNa and ESPNIC (Nursing), of adult, paediatric and neonatal critical care nurses investigated their experiences and views of family members' presence during CPR (Fulbrook et al., 2005; Fulbrook et al., 2007). These studies indicated that most European critical care nurses were supportive of

\section{EFCCNa, ESPNIC and CCNAP POSITION}

1. All patients have the right to have family members present during resuscitation.

See Note 1, below.

2. The patient's family members should be offered the opportunity to be present during resuscitation of a relative.

See Note 2, below.

3. Support should be provided by an appropriately qualified health care professional whose responsibility is to care for family members witnessing cardiopulmonary resuscitation.

See Note 3, below.

4. Professional counselling should be offered to family members who have witnessed a resuscitation event.

5. All members of the resuscitation team who were involved in a resuscitation attempt when family members were present should participate in team debriefing.

6. Family presence during resuscitation should be incorporated into the curricula of cardiopulmonary resuscitation training programmes.

7. All intensive and critical care units should have multi-disciplinary written guidelines on the presence of family members during cardiopulmonary resuscitation.

\section{NOTES}

Note 1

The decision to enable family members to be present during a resuscitation attempt should be made in the best interests of the person who is being resuscitated. In this regard, discussion should be facilitated by experienced healthcare professionals. When appropriate, spiritual leaders or other trained members of the health care team may assume this role. If the patient who is being resuscitated has expressed a prior wish, this should be respected.

Note 2

When the person who is being resuscitated is not able to communicate his or her wishes, or who has not previously expressed their wishes in an advanced directive, the decision about who should be present during resuscitation should be made jointly by the members of the resuscitation team and family members.

The decision of a family member about whether or not to be present during CPR of a relative should be made freely by the family member, without coercion or pressure.

Family members should be warned that on occasions they may be asked to leave the bedside if at any time it is thought to be in their or the patient's best interests, for example, for the purpose of obtaining radiographs or to avoid obstructing the work of the resuscitation team.

Europe is multi-culturally diverse, and the resuscitation team should take the individual patient's and family's beliefs, values and rituals into account. The patient's and the family's cultural background should be assessed with respect to the provision of appropriate individualised care.

Note 3

Whilst it is conceded that on some occasions it may not be possible to provide a health care professional whose sole responsibility is to care for the family member, this should not mean the exclusion of the family member from the resuscitation. Rather, an experienced member of the resuscitation team, who is not undertaking a lead role, should be designated primary responsibility for the continued care of the family member.

With respect to family members, the role of the designated health care professional is to:

- brief them about what to expect prior to entering the resuscitation area,

- provide a running commentary with appropriate explanations,

- help them to communicate their presence to their relative,

- respond truthfully and realistically to questions,

- maintain a safe environment,

- assess continually their emotional and physical status,

- if possible, accompany the family member if he or she wishes to leaves the scene, continuing to liaise with the resuscitation team on their behalf,

- provide an opportunity for them to reflect on the resuscitation process after the event, participate in resuscitation team debriefing, providing feedback with respect to the needs and concerns expressed by them. 
family-witnessed CPR. However, only a small number of intensive care units had resuscitation policies that included guidance about family members' presence. As a result a major recommendation from both surveys was for this lack of directive to be addressed at a Europe-wide level.

Although there is some evidence to indicate that that not all European countries are supportive of family member presence (Badir \& Sepit, 2007), in the light of the general consensus found in the two European surveys (Fulbrook et al., 2005; Fulbrook et al., 2007), and current guidance from the European Resuscitation Council (Baskett et al., 2005) it is reasonable that EfCCNa, ESPNIC and CCNAP should state their position on family presence during CPR. However, further research related to family presence during resuscitation and its impact on patients, family members and health care professionals is required.

\section{POSITION STATEMENT}

The EfCCNa, ESPNIC and CCNAP Position is stated above. It provides a series of statements about family presence during CPR. The Position is underpinned by the belief that family members are critical to the health and wellbeing of the patient.

For the purpose of this Position Statement the following definitions are used:

- Cardiopulmonary resuscitation: life-saving interventions when either cardiopulmonary or respiratory arrest occurs.

- Intensive and critical care setting: any in-hospital acute care setting where critically ill patients (children and adults of all ages) are cared for.

- Family member: those people who are most important to the patient. This definition includes the patient's family, loved ones and close friends. For newborns and children this is defined as the parents or significant others.

- Family presence: family member presence during CPR, including the witnessing of all life-saving interventions.

\section{FURTHER INFORMATION}

For further information about this Position Statement please contact:

EfCCNa: John Albarran - E-mail john.albarran@uwe.ac.uk

ESPNIC: Jos Latour - E-mail j.latour@erasmusmc.nl

CCNAP: Tone Norekvål - E-mail tone.norekval@helse-bergen.no

\section{REFERENCES}

Albarran JW, Stafford H (1999). Resuscitation and family presence: Implications for nurses in critical care areas. Advancing Clinical Nursing 3 (1), 11-20.

Badir A, Sepit D (2007). Family presence during CPR: a study of the experience and opinions of Turkish critical care nurses. International Journal of Nursing Studies 44 (1), 83-92.

Barratt F, Wallis DN (1998). Relatives in the resuscitation room: Their point of view. Journal of Accident and Emergency Medicine 15 (2), 109-111.

Baskett PJF, Steen PA, Bossaert L (2005). European Council Guidelines for Resuscitation 2005. Section 8 . The ethics of resuscitation and end-of-life decisions. Resuscitation 67 (Supplement 1), S171-S180.

Blair $\mathrm{P}$ (2004). Is family presence practical during emergency resuscitation? Nursing Management 35 (6), 20, 23.

Boyd R (2000). Witnessed resuscitation by relatives. Resuscitation 43 (3), 171-176.

Crisci C (1994). Local factors may influence decision (letter). BMJ 309 (6951), 406.

Eichhorn DJ, Meyers TA, Guzzetta CE, Clark AP, Klein JD, Talieaferro E, Calvin AO (2001). Family presence during invasive procedures and resuscitation: hearing the voice of the patient. American Journal of Nursing 101 (5), 48-55.

Fein JA, Ganesh J, Alpern ER (2004). Medical staff attitudes toward family presence during pediatric procedures. Pediatric Emergency Care 20 (4), 224-227.

Fulbrook P, Albarran JW, Latour JM (2005). A European survey of critical care nurses' attitudes and experiences of having family members present during cardiopulmonary resuscitation. International Journal of Nursing Studies 42 (5), 557-568.

Fulbrook P, Latour JM, Albarran JW (2007). Paediatric critical care nurses' attitudes and experiences of parental presence during cardiopulmonary resuscitation: a European survey. International Journal of Nursing Studies 44 (7), 1238-1249.

Grice AS, Picton P, Deakin CD (2003). Study examining attitudes of staff, patients and relatives to witnessed resuscitation in adult intensive care units. British Journal of Anaesthesia 91 (6), 820-824.

Gold KJ, Gorenflo DW, Thomas L, Schwenk TL, Bratton SL (2006). Physician experience with family during cardiopulmonary resuscitation in children. Paediatric Critical Care Medicine 7 (5), 428433.

Gulla JM, Twist M, Singer A (2004). Should families be present during resuscitation? (Abstract). Annals of Emergency Medicine 44 (4), S67.

Holzhauser K, Finucane J, Vries de SM (2006). Family presence during resuscitation: A randomized controlled trial of the impact of family presence. Australian Emergency Nursing Journal 8 (4), 139-147.

Jarvis AS (1998). Parental presence during resuscitation: attitudes of staff on a paediatric intensive care unit. Intensive and Critical Care Nursing 4 (1), 3-7.

Kissoon N (2006). Family presence during cardiopulmonary resuscitation: our anxiety versus theirs. Paediatric Critical Care Medicine 7 (5), 488-491.

Mazer MA, Cox LA, Capon A (2006). The public's attitude and perception concerning witnessed cardiopulmonary resuscitation. Critical Care Medicine 34 (12), 2925-2928.

McClenathan BM, Torrington KG, Uyehara CFT (2002). Family member presence during cardiopulmonary resuscitation: A survey of US and international critical care professionals. Chest 122 (6), 2204-2211.

Meyers TA, Eichhorn DF, Guzetta CE, Clarke A, Klein J, Taliferro E, Clavin A (2000). Family presence during invasive procedures and resuscitation: the experience of family members, nurses, and physicians. American Journal of Nursing 100 (2), 32-42.

Robinson SM, Mackenzie-Ross S, Campbell Hewson GL, Egleston CV, Prevost AT (1998). Psychological effect of witnessed resuscitation on bereaved relatives. The Lancet 352 (9128), 614-617.

Schilling RJ (1994). Should relatives watch resuscitation? No room for spectators (letter). BMJ 309 (6951), 406.

Tasker RC (2005). Inter-hospital transport for children and their parent(s). Archives of Disease in Childhood 90 (12), 1217-1218.

Tsai E (2002). Should family members be present during cardiopulmonary resuscitation? New England Journal of Medicine 346 (13), 1019-1021.

Van der Woning M (1999). Relatives in the resuscitation area: a phenomenological study. Nursing in Critical Care 4 (4), 186-192.

Wagner JM (2004). Lived experience of critically ill patients' family members during cardiopulmonary resuscitation. American Journal of Critical Care 13 (5), 416-420.

Walker WM (1999). Do relatives have a right to witness resuscitation? Journal of Clinical Nursing 8 (6), 625-630.

Walker WM (2006). Witnessed resuscitation: A concept analysis. International Journal of Nursing Studies 43 (3), 377-387.

Weslien M, Nilstun T, Lundqvist A, Fridlund B (2006). Narratives about resuscitation - Family members differ about presence. European Journal of Cardiovascular Nursing 5 (1), 68-74. 